\title{
A BIOPOLÍTICA NOS ARQUIVOS: Vigilância e risco
}

\author{
BIOPOLITICS IN ARCHIVES: \\ Surveillance and risk
}

Derek Warwick da Silva Tavares ${ }^{1}$

José Mauro Matheus Loureiro²

\section{RESUMO}

Este presente artigo trata-se de uma pesquisa teórica sobre os efeitos biopolíticos nos arquivos. Apresenta as dimensões do poder e da disciplina na formação de documentos e arquivos, bem como relaciona as ações e os efeitos de vigilância a partir da noção sociológica de risco. No estudo, o arquivo é apresentado como elemento que possui em si mesmo a potência de governo, capaz de atuar no campo auxiliar dos mecanismos reguladores do Estado. Nesse sentido, o estudo objetiva identificar e descrever o vínculo biopolítico do arquivo na modernidade. Para tanto, emprega-se, neste artigo, uma metodologia de caráter qualitativo, com delineamento bibliográfico na problematização e articulação de elementos teóricos, conceituais e analíticos, oriundos dos campos filosóficos, sociológicos, históricos e arquivísticos. Conclui-se, então, que 0 efeito biopolítico no arquivo atua na indexação de práticas sociais e dos sujeitos maximizando seus efeitos através do reconhecimento de tudo aquilo que é possível registrar, classificar, representar, conservar e disseminar.

Palavras-chave: Arquivo. Biopolítica. Vigilância. Risco. Informação.

\section{ABSTRACT}

This article is a theoretical research on the biopolitical effects in archives. It presents the dimensions of power and discipline in the formation of documents and archives, as well as relates the actions and effects of surveillance from the sociological notion of risk. In this study, the archive is presented as an element that has in itself the potency of government, capable of acting in the auxiliary field of the State's regulatory mechanisms. In this sense, the study aims to identify and describe the biopolitical bond of the archive in modernity. For this purpose, it is used in this article a qualitative methodology, with a bibliographic approach in the problematization and articulation of theoretical, conceptual and analytical elements, originated from the philosophical, sociological, historical and archivistics studies. It is concluded, then, that the biopolitical effect in the archive acts in the indexation of social practices and of the subjects maximizing its effects through the recognition of everything that is possible to register, classify, represent, conserve and disseminate.

Keywords: Archive. Biopolitics. Surveillance. Risk. Information.

Artigo submetido em 19/07/2020 e aceito para submissão em 25/07/2020

1 Professor do Instituto de Ciência da Informação da Universidade Federal da Bahia, Brasil. ORCID https://orcid.org/0000-0002-11593652. E-mail: dws.tavares@gmail.com

2 Professor da Universidade Federal do Estado do Rio de Janeiro, Brasil. ORCID https://orcid.org/0000-0003-4714-5437. E-mail: jmm.loureiro@gmail.com 


\section{INTRODUÇÃO}

Cotidianamente relacionamo-nos com diversificados objetos materiais e imateriais passíveis de constituição dos acervos arquivísticos. Na construção de tais acervos encontram-se vinculadas relações políticas, econômicas, financeiras, que os tornam capazes de incorporarem os quadros da memória social a partir de inúmeras estratégias de gestão e disponibilização para o público em geral. Tais estratégias obedecem a uma "vontade de arquivo" (TAVARES, 2015, p. 72), cuja interpenetração de normas, pragmáticas e conhecimentos específicos promovem a forma, a qualidade, o direcionamento e a definição daquilo que será criado, arquivado e eliminado em um conjunto documental.

Tais conjuntos documentais, quando reunidos em uma unidade espacial específica de vinculação com o produtor e com a utilização de técnicas e procedimentos de guarda e organização, estabelecem por um determinado momento, um estatuto de verdade, ou regimes de veridicção a partir de formas hermenêuticas de interpretação e representação documental (DERRIDA, 2001). Esta reunião constitui uma instituição denominada "arquivo", cuja multiplicidade de significações espaciais conformam sua natureza heterotópica e racionalizada, sobretudo, para o cumprimento das ações de governamentalidade dos órgãos oficiais os quais conferem formaç̧ão, atuação e transformação do Estado.

Neste sentido, a constituição das regras, práticas e regimes de governo não se efetuam de maneira centralizada pelo Estado, mas obedecem a uma precedência distributiva do poder entre as esferas públicas e privadas que compõem a sociedade civil (DEAN, 1999). Tais organismos públicos e privados constituem-se instrumentos "independentes-vinculantes" (empresas, ONGs, dentre outros) do Estado configurados como dispositivos institucionais atuantes na cooperação e articulação das atividades anteriormente de exclusividade estatal, tais como: rotinas burocráticas, tecnologias de registro de notação, compilação, apresentação, transporte, tratamento e gerenciamento info-comunicacional.

Nestes espaços institucionais, públicos e privados, "a qualidade conectiva dos traços escritos é ainda mais visível no mais desprezado dos objetos etnográficos: 0 arquivo ou registro" (LATOUR, 2015, p. 26). Evidencia-se, assim, que "a racionalização atribuída à burocracia desde Hegel e Weber tem sido atribuída por erro à mente dos burocratas (prussianos). Mas está tudo nos arquivos mesmos" (LATOUR, 2015, p. 26, grifo do autor).

As diversificadas ações estatais em suas relações com 0 arquivo, utiliza um número cada vez maior de documentos, conferindo a este espaço participação nas esferas argumentativas e técnicas de domínio e execução da sua administração, na manutenção e controle das relações de poder. Nesse 
sentido, o arquivo possui em si mesmo a potência de governo ou um devir governo, sobretudo quando se sabe que "nunca se governa uma estrutura política. Quem é governado são sempre pessoas, são homens, são indivíduos ou coletividades" (FOUCAULT, 2008, p. 164).

Assim considerando, objetiva-se identificar e descrever o vínculo biopolítico do arquivo na modernidade. Para tanto, emprega-se metodologia de caráter qualitativo, com delineamento bibliográfico de uso restrito de fontes secundárias, que articulam elementos teóricos, conceituais e analíticos que substanciam o empreendimento procedimental da investigação em nível descritivo.

Em vista disso, consideramos de início que o arquivo estaria inserido no campo auxiliar dos mecanismos reguladores das técnicas de polícia e governamentalização que mantêm estáveis as condições de governo do Estado, a partir de procedimentos a priori de gerenciamento da produção, acesso, organização e captura de informações da atualidade e do passado remoto ou próximo do homem-espécie, oferecendo a posteriori, possíveis pragmáticas memorialísticas e discursivas de caráter social, político e identitário.

\section{PODER E DISCIPLINA NA FORMAÇÃO DE REGISTROS E ARQUIVOS}

Na Idade Moderna o arquivo aprofunda seus vínculos políticos com o Estado em virtude da ampliação das atividades e necessidades de conhecimento relacionadas à população, ao território e à garantia da soberania. Essa dinâmica tem como inspiração o modelo romano cuja formação privilegiava a centralização e controle das atividades do Estado, seus agentes e transformando os governantes em burocratas. Essa tendência, segundo Burke (2003), ocorre devido à adoção de um sentido administrativo conhecido no século XVI por "poder dos secretários". De certa forma, este poder, caracterizado pelo acumulo de informação estará associado ao "desejo crescente dos governantes de controlar as vidas do povo em geral, fosse para aumentar os impostos, alistá-lo no exército ou alimentá-lo em tempos de fome. (BURKE, 2003, p. 112). Em mesmo sentido, esta abordagem se aproximaria do modelo de administração objetivado por Max Weber de Burocracia. Nesta, a função de registro opera significativa relevância na execução administrativa do Estado, sobretudo, quando se considera que "a administração moderna baseia-se em documentos (atas), cujo original ou rascunho se guarda, e em um quadro de funcionários subalternos e escrivães de todas as espécies" (WEBER, 2012, p. 199). 
Estes cenários, de "poder dos secretários" e "burocracia", remetem à noção de "poder disciplinar", enquanto um mecanismo que opera através de técnicas de poder, punição e vigilância dedicadas à garantia da boa conduta dos indivíduos, de tal forma que:

[...] 0 poder disciplinar é [...] um poder que, em vez de se apropriar e de retirar, tem como função maior "adestrar": ou sem dúvida adestrar para retirar e se apropriar ainda mais e melhor. Ele não amarra as forças para reduzi-las; procura ligá-las para multiplicá-las e utilizálas num todo. [...] "Adestra" as multidões confusas [...] (FOUCAULT, 2005, p. 143).

As "sociedades disciplinares" agem sobre os homens em múltiplas dimensões estratégicas de normalização das condutas individuais e coletivas, o que torna imperativo nos grupos sociais a existência de mecanismos de vigilância e produção da verdade. A vigilância demonstra o refinamento das ações de poder disciplinar, uma vez que não será necessário atuar por intermédio da dor, violência, mas nos gestos dos indivíduos. As "disciplinas", neste momento, seriam "métodos que permitem 0 controle minucioso das operações do corpo, que realizam a sujeição constante de suas forças e lhes impõem uma relação de docilidade-utilidade" (FOUCAULT, 2004, p. 126).

A "disciplina”, de acordo com Machado (1982, p. 195), possui quatro características interrelacionais que permitem agir como instrumento de poder. Ela é organizacional nos modos de identificação, classificação e distribuição dos indivíduos no espaço social; temporal no desenvolvimento de suas ações articuladas com o corpo; vigilante nas condutas que absorvem a ideia contínua e permanente da vigilância; e por fim, registradora de conhecimentos, a partir da ideia de que "o olhar que observa para controlar não é o mesmo que extrai, anota e transfere as informações para os pontos mais altos da hierarquia de poder?" (MACHADO, 1982, p. 195).

Essa categoria de poder evidencia-se no modelo de controle da peste, como uma estratégia de defesa social, onde se exclui através do controle refinado e localizado dos indivíduos. À época esta prática promovia o encarceramento por meio da demarcação de território em distritos, quarteirões e ruas, sob a responsabilidade de vigias e inspetores que analisavam minuciosamente, no interior de cada espaço de ocupação, os corpos sadios, doentes e mortos. A vigilância, entretanto, se apoia num sistema de registro permanente de nomes, idade, sexo, doenças, reclamações, irregularidades as quais percorrem um ciclo de uso que opera entre a figura do intendente do quarteirão, o escritório da prefeitura, os magistrados e médicos (FOUCAULT, 2004, p. 174). Essa conduta revela estratégias para garantir o melhor conhecimento em matéria de disciplina, vigilância e, portanto, controle da vida. Tais empreendimentos configurariam, neste caso, o aspecto embrionário de um comportamento biopolítico do arquivo. Dessa maneira, a biopolítica é entendida como "a maneira pela qual, a partir do século 
XVIII, se buscou racionalizar os problemas colocados para a prática governamental pelos fenômenos próprios de um conjunto de viventes enquanto população: saúde, higiene, natalidade, longevidade raça" (CASTR0, 2009, p. 59).

Enquanto as bibliotecas no século XVII atuavam como espaço de sociabilidade e progresso do saber universal, os arquivos voltavam-se para os elementos burocráticos da administração e do segredo da informação, semelhante às arcana imperii (segredos de Estado), que estimulava o entendimento e a prática de que "o monopólio da informação (pelo menos de alguns tipos de informação) era um meio de alcançar o monopólio do poder" (BURKE, 2003, p. 129). Haveria assim, segundo Burke (2003), dois tipos de informação: uma de natureza científica e outra de natureza administrativa. A primeira, evidência os sujeitos vinculados aos ofícios do saber, às bibliotecas, museus e às estratégias de difusão da informação; perspectiva que o autor denomina de acadêmica. A segunda, compreende a informação como inserida em uma política do conhecimento, sendo necessário para a sua construção implementar atividades de coleta, armazenamento, tratamento, sigilo e recuperação pelas autoridades de Estado e Igreja, o que inspira uma tendência de surgimento de um "Estado de Vigilância".

Na prática, coletavam informações para responder a problemas ou crises específicas, como sedição, pestes e guerras, ainda que uma tendência de longo prazo à coleta de informações para apoiar as práticas rotineiras de governo também seja discernível, especialmente de 1650 em diante. (BURKE, 2003, p. 110).

Gottfried Wilhelm Leibniz (1646-1716) em obra intitulada "Sobre a instituição útil de um arquivo" (Von nützlicher Einrichtung eines Archivi), reconhecia no arquivo um espaço de manutenção e tradição da escrita, e do gerenciamento do conhecimento, por meio do qual o governante tornavase informado não apenas sobre conhecimentos gerais e científicos (Wissenschaft), mas também de informações contextuais específicas (Besondere Nachrichtungen), a exemplo das instituições políticas e tradições culturais de cada território (FRIEDRICH, 2018, p. 69).

A dimensão da informação e do conhecimento, nesse contexto, situava-se entre aqueles que possuíam ou adquiriam o "ofício do saber". Procurando conhecer os súditos e o território, civilizações da antiguidade e do período medieval, produziram grandes registros na forma de censos territoriais, urbanos, fiscais e militares objetivando atender às necessidades de governo e administração dos reinos e impérios. Destaca-se, no contexto ocidental, o papel exercido no medievo pela Igreja Católica Apostólica Romana nesse período, sobretudo, no critério da elevação do número de documentos produzidos. Essa instituição possuía enorme poder, influência e capacidade de atuar sob as formas de governo administrativo, jurídico e político da época. Parte de suas principais ações em matéria de documentos e arquivos ocorreu em 
decorrência, por exemplo, do IV Concílio de Latrão (1215), no qual o Papa Inocêncio III, como forma de garantir a legalidade dos procedimentos jurídicos em suas etapas de julgamento, define que estes atos deveriam ser documentados por escrito. Outro exemplo das ações da igreja nos quesitos documentais e de registros são determinados pelo Concílio de Trento (1563) no qual determina-se a manutenção de registros de nascimento, morte e casamentos, e ainda das condições físicas, educacionais e espirituais das paróquias (BURKE, 2003). A fim de cumprirem tais objetivos são formulados questionários que, posteriormente, impulsionaram a realização de grandes censos.

Todos esses registros coletados em um regime de controle constituiriam, principalmente durante o período inquisitorial, um grande "banco de dados" por meio do qual seria possível obter informações de ampla natureza, mais especificamente acerca da idade, lugar de nascimento, ocupação, crenças, dentre outros (BURKE, 2003, p. 114). Tais procedimentos ocorreram em meio ao contexto de surgimento daquilo que Burke (1997) denomina de "alfabetização pragmática" a qual se diferencia das formas litúrgicas e literárias de escrita. Este tipo de alfabetização teria seus primórdios, segundo a historiografia tradicional, na transição entre a Alta e a Baixa Idade Média do século XII, conjuntura em que se eleva quantitativamente a produção de documentos que registravam relações sociais, administrativas e de negócios, além do domínio da produção do suporte papel em substituição ao pergaminho.

Essa expansão da escrita é acompanhada da elevação da produção de documentos notariais de natureza legal, de crédito e de posse, sobretudo nos centros urbanos, a partir do século XII. Por outro lado, 0 Estado e seus governantes, diante da expansão dos reinos, mais interessados em conhecer e controlar cada vez mais o território e a população, aderem ao formato de correspondências diplomáticas de comunicação com embaixadores estrangeiros e ao modelo censitário de relatórios de viagens. Tais documentos constituíam-se adaptações dos questionários religiosos realizados por funcionários que buscavam, através de excursões, localizar, coletar informações noticiosas e descritivas acerca das atividades festivas e religiosas dos habitantes, bem como inventariar contas financeiras e militares do território, com base ainda em “questões práticas da administração, privilégios, qualidade das terras e número de hospitais” (BURKE, 2003, p. 120). Durante o reinado de Filipe II de Espanha (1556-1598), por exemplo, "foram feitos relatórios detalhados, hoje conhecidos como Relaciones topográficas, de aproximadamente 600 (seiscentos) vilarejos em uma região da Espanha, Nova Castela" (BURKE, 2003, p. 120).

Este conjunto de práticas dará origem ao uso administrativo e militar das cartografias como elemento estratégico de governo, através da definição de fronteiras, defesa do território e racionalização administrativa. Ilustra o emprego dessas práticas o interesse de Leibniz (1646-1716) pela problemática 
das informações topográficas, que desempenhavam um papel cada vez mais significativo nos governos, ao se colocarem a serviço do governante a partir de uma teoria da ação política baseada no conhecimento, sobretudo, quando atuou como conselheiro de Leopoldo I (1640-1705), Imperador do Sacro Império Romano-Germânico, entre os anos de 1658 e 1705. 0 seu modelo, que combinava a coleta e apresentação das informações em formatos de tabelas, denominadas de "tabelas de Estado" (Staatstafeln), garantia ao arquivo o seu reconhecimento enquanto uma tipologia do conhecimento útil, baseada na legalidade e relevância dos registros e da informação. Para o autor, um arquivo serve, portanto, "para fornecer tanto informações fora dos tribunais quanto provas no tribunal” (FRIEDRICH, 2018, p. 69).

Assim, do século XVI ao XVIII as formas de produção de registros adquirem designação de uso político, além do administrativo, em decorrência da natureza das informações obtidas, tais como: dados sobre nascimento, morte, casamentos, doenças. Nestes termos:

Em meados do século XVII, na República Holandesa, o advogado e estadista Jan de Witt já utilizava números relativos à mortalidade para estabelecer um sistema de anuidades administrado pelo governo. Na Suécia, onde o governo tinha interesse em estimular 0 crescimento da população com base no princípio de que "o número de pessoas é a maior riqueza de um país", determinou-se em 1736 que o clero fornecesse anualmente os números de nascimentos e mortes em suas paróquias, e um censo nacional foi realizado em 1748. (BURKE, 2003, p. 125).

Assim considerando, os arquivos tornam-se dispositivos de informação necessários à efetiva atuação e manutenção política, a partir dos seus múltiplos conhecimentos seletivos em diversas áreas do campo administrativo, jurídico, científico e histórico, servindo ainda de instrumento educador dos príncipes em matérias de erudição, moral e história política baseadas nas informações do passado.

Consequentemente, reconhecida a preocupação em manter sob uma unidade organizacional os documentos, a formação dos arquivos, enquanto espaços institucionais, toma como referência ainda 0 critério da preservação e segurança dos registros. Reconhecendo, porém, que esta preocupação não é um critério específico do arquivo institucional, propomos outro elemento no cenário formador dos arquivos institucionais - a noção do panoptismo.

\section{A DIMENSÃO PANÓPTICA dO ARQUIVO}

No século XVIII, vinculado ao princípio de registro das condutas, Jeremy Bentham (1748-1832) projetou o panóptico como um "espaço não demasiadamente grande para que possa ser controlado ou dirigido a partir de edifícios, queira-se manter sob inspeção um certo número de pessoas" (BENTHAM, 2008, p. 19). Seu projeto foi desenvolvido para locais bastantes específicos, tais como: prisões, casas 
de correção, hospícios, hospitais, indústrias/manufaturas e escolas. Esta vigilância foi planejada para ocorrer de maneira constante, de modo que os indivíduos se sintam sob vigilância permanente.

Para a efetivação de tal projeto, seria imperativo tornar tudo visível e, simultaneamente, tornarse ele mesmo invisível. Essa estrutura denominada de "Panóptico", antes de ser uma construção, é uma ideia, um projeto, um princípio de vigilância por meio do qual se torna possível ver sem ser visto. É um princípio econômico que oferece uma "vantagem muito importante - é aquela que diz respeito ao número de inspetores exigidos" (BENTHAM, 2008, p. 31). Em outras palavras, tem por característica reduzir a vigilância ao mesmo tempo em que mantém sob o olhar atento de um vigilante que, escondido na sombra, intensifica o seu poder. Desse modo, a economia se vincula no nível pessoal ou instrumental, já que para garantir a vigilância de muitos bastaria a presença de apenas um inspetor, ou tempos atuais, de uma câmera de segurança.

Esse princípio pode ser associado ao estudo realizado por Barry, Osborne e Rose (1996, p. 102, tradução nossa), que fundamentados por diversos autores afirmam:

A partir da década de 1830, havia uma preocupação em traçar a dinâmica e as características das populações; "Estamos a olhar para uma sociedade que de repente conheceu muito mais sobre si" (GOLDMAN,1991, p. 420). 0 gatilho para isso foi a reforma da Lei dos Pobres no início da década de 1830 e toda uma série de investigações e inquéritos que se seguiram. As circunstâncias da nação tornaram-se um arquivo gigante; não apenas pelas atenções das Comissões reais e dos Comités Seletivos (CLOKIE; ROBINSON, 1937, p. 97-114), mas para as inspetorias famosas envolvidas com fábricas, prisões, escolas, ferrovias e minas (YOUNG, 1936, p. 57).

Não sendo possível, dessa maneira, a inspeção contínua e permanente, o modelo do panóptico fará com que esta inspeção ocorra no interior de múltiplos dispositivos, a exemplo do arquivo, que teria a função específica de inspecionar, através do registro, todas as ações e coisas possíveis. Ketelaar (2007) oferece o exemplo da Holanda no século XVIII a partir da constituição em 1798 de um único Estado-nação, em consequência do fim da República Federativa dos Países Baixos Unidos. Sob a forte influência de uma burocracia de Estado, que impulsionava a produção de registros e documentos, 0 autor afirma que "o volume de arquivos criado no chamado período Batavian-French (1795-1813) na província da Frísia é de 172 metros de corrida, o que equivale a 50\% de todos os registros do governo criados naquela província durante os trezentos anos anteriores" (KETELAAR, 2007, p. 144, tradução nossa).

Diante da premente necessidade do Estado em obter informações para o conhecimento amplo e irrestrito da população, ocorreu um crescimento exponencial de documentos que foi acompanhado pelo desenvolvimento e utilização de técnicas arquivísticas para o armazenamento e recuperação da 
informação. Nesse contexto, o arquivo se incorpora às redes de vigilância e conhecimento a partir da prerrogativa do registro e arquivamento, de modo que "arquivos de arquivos podem ser gerados e esse processo pode ser continuado até que alguns homens considerem milhões como se estivessem nas palmas de suas mãos" (LATOUR, 2015, p. 26, tradução nossa).

0 arquivo panóptico, desse modo, torna-se um espaço heterotópico determinado a produzir, guardar, conservar, disciplinar e controlar o conhecimento registrado em seu conteúdo, forma, estrutura e capacidade de ação, sob a forma de uma vigilância visível e oculta ao mesmo tempo. Assim, seu poder panóptico, enquanto dispositivo maquínico de visibilidade e enunciação faz com que seus registros e inscrições "possam ser sobrepostos, reorganizados, recombinados e resumidos, e que fenômenos totalmente novos aflorem, ocultos das outras pessoas de quem todas essas inscrições foram exigidas” (LATOUR, 2015, p. 30, tradução nossa).

Assim, "o panóptico é um local privilegiado para tornar possível a experiência com homens, e para analisar com toda certeza as transformações que se pode obter neles" (FOUCAULT, 2004, p. 169). Do mesmo modo, é possível perceber no arquivo a articulação de teorias, técnicas e fluxos informacionais que promovem efeitos de enunciação e visibilidade do discurso, capazes de governar os homens em torno das suas necessidades e dos aspectos de identidade, cultura e poder. Estes aspectos tornam-se amplos quando consideramos a atualização do modelo edificante do panoptico em uma modelagem aberta e digital do panoptic sort.

\subsection{Panoptic Sort: os arquivos binários/digitais}

Na atualidade, o conceito de "Panoptic Sort", proposto por Gandy Jr. (1993) caracteriza as tecnologias e sistemas discriminatórios de vigilância que operam, através de instrumentos de coleta e compartilhamento de informações, potências de comportamento de consumo, social e político, para controle de acesso, uso e comercialização de produtos e serviços, mediante ações analíticas relacionais de identificação, classificação e avaliação.

A identificação refere-se à necessidade dos organismos "independente-vinculantes" obterem informações confiáveis acerca da identidade dos indivíduos, tais como: nome, endereço, telefone, parentesco, perfil de consumo, dentre outros. A classificação é a atividade consequente da identificação que, estando completamente envolvida no exercício do poder, atua na segmentação de indivíduos locados em grupos, definindo assim, tipos de indivíduos, ou usuários, que compartilham 
características e informações semelhantes, com a finalidade de disciplinar, tal como ocorre nos espaços da prisão, hospital e escola. Envolvida na classificação, a avaliação busca reduzir a complexidade das informações, tornando-as acessíveis para a inclusão ou exclusão dos indivíduos em determinados fluxos informacionais (GANDY JR., 1996, p. 135-136).

Esta abordagem é passivelmente de ser extendida em outra noção operatória, apresentada por Zuboff (1988) a partir da análise de sistemas de informação, que a autora considera como instrumento panóptico de informacão, que:

Livres das restrições de tempo e espaço, não dependem de arranjos físicos de construções ou da guarda trabalhosa de registros da administração industrial. Eles não requerem a presença mútua de objetos de observação. Eles não requerem, nem ao menos, a presença de um observador. (ZUBOFF, 1988, p. 322).

Tais sistemas de informação, amplamente aperfeiçoados entre os anos de 1965 e 1985, segundo Clarke (1988), inverteram o paradigma das tecnologias de informação, que outrora dedicadaa o processamento e centralização de dados, darão lugar ao imperativo dos dados operados em redes descentralizadas de controle e gerenciamento. Esta abordagem que assimila os sistemas de informação às políticas de dados será definida por Clarke (1988) a partir do neologismo que congrega os termos data (dados) e surveillance (vigilância) na formação da palavra dataveillance. 0 autor define a expressão "vigilância de dados" como sendo "o uso sistemático de sistemas de dados pessoais na investigação ou monitoramento das ações ou comunicações de uma ou mais pessoas" (CLARKE, 1988, p. 499, tradução nossa).

Contudo, ao considerar, já no século XXI, o aparecimento de uma categoria sustentada por dados de transações pessoais, denominada digital personal, Clarke e Greenleaf (2017, p. 2, tradução nossa) compreenderão que "enquanto a vigilância física tem seu foco no corpo e no comportamento do indivíduo, a vigilância de dados observa a sombra que a pessoa lança ao realizar transações, de natureza econômica, social ou política". Dessa forma, ao reposicionar a vigilância de dados não mais nos sistemas de informação, mas nos dados pessoais, os autores defendem que "a vigilância de dados é a criação e/ou uso sistemático de dados pessoais para a investigação ou monitoramento das ações ou comunicações de uma ou mais pessoas" (CLARKE; GREENLEAF, 2017, p. 3, tradução nossa).

Neste cenário, a regulação e a vigilância são praticadas de forma dispersiva pelas múltiplas associações dos órgãos independentes-vinculantes e pelos cidadãos, que segundo Poster (2007, p 96), ao preencherem formulários "eles são, ao mesmo tempo, fontes da informação e registradores da informação". Esta ação individual ocorre por intermédio da prerrogativa da autonomia, do indivíduo de vontade, e, portanto, livre. 
Os cidadãos estão posicionados nos discursos governamentais, portanto, como sujeitos ativos e não passivos de governança. Ao invés de serem policiados externamente por agentes do estado, os indivíduos policiam-se, exercem poder sobre si mesmos como sujeitos normalizados que estão em busca de seus próprios interesses e liberdade, interessados em autoaperfeiçoamento, buscando felicidade e saúde. (LUPTON, 2013, p. 119, tradução nossa).

A participação efetiva dos indivíduos no processo de vigilância faz com que Poster (2007) considere que estaríamos falando de ações individuais normalizadoras e autoconstituintes de um "Superpanopticon" de carecterísticas pós-industriais, cujo elemento fundamental, a informação, opera em função mediadora entre os indivíduos e os sistemas de informação, sendo capaz de alterar a estrutura e as condições subjacentes ao processo comunicional. Assim,

Vemos os bancos de dados não como uma invasão da privacidade, como uma ameaça a um indivíduo centrado, mas como a multiplicação do indivíduo, a constituição de um eu adicional, que pode ser acionado em detrimento do eu "real" sem isso. Eu "real" sempre consciente do que está acontecendo. (POSTER, 2007, p. 100).

Dessa forma, a perspectiva do Panoptic Sort(GANDYJR., 1988), a "vigilância de dados" (CLARKE, 1988; CLARKE; GREENLEAF, 2017) e o "Superpanótico" (POSTER, 2007) encontram ressonância na "governamentalidade" contemporânea, instrumentalizada em meio a grupos dispersos da população, caracterizados por uma multiplicidade de sujeitos e informações que ensejam o aparecimento da noção de "perfil" que "é supra-individual e criado a partir de informações brutas e infra-individuais" (PARRA, 2016, p. 41). Nessa perspectiva, acrescenta-se o que Rouvroy e Berns (2015) a partir de um modelo governamental que atua através do uso algorítmico de dados e informações na contemporaneidade, chamam de "governamentalidade algorítmica", ou seja:

Um modo de governo alimentado essencialmente por dados brutos (que operam como sinais infra-pessoais e a-significantes mas quantificáveis); que afetam os indivíduos sob o modo de alerta, provocando o reflexo, mais do que sob o modo da autorização, proibição ou persuasão, ao se apoiar sobre suas capacidades de entendimento e de vontade; visando essencialmente a antecipar o futuro, a limitar o possível, muito mais do que regulamentar as condutas. Os dispositivos da governamentalidade algorítmica integram o data-mining: a exploração das reservas de dados massivos e brutos, que individualmente não possuem nenhum sentido, para a partir deles traçar perfis de comportamento (PARRA, 2016, p. 41).

A utilização deste modelo como estratégia confere o poder de vigilância associado à ideia de risco enquanto um elemento circunstancial das formações discursivas e das práticas históricas, sociais, políticas e culturais, uma vez que "através da nova tecnologia dos riscos, o controle social e a disciplina passam a apoiar-se cada vez mais sobre as estratégias heterogêneas de autovigilância e de vigilância externa" (CALIMAN; TAVARES, 2013, p. 938, apud CLARKE et al., 2000). Por esse ângulo, teríamos como exemplo o boom informacional e documental do século XX, no qual 0 arquivo encontrou-se 
inserido em sua tarefa de registrar as possibilidades de execução de controle do risco a partir da gestão de documentos.

\subsection{0 "Risco" como racionalidade de arquivo}

Reconhecendo a dificuldade de situar a origem etimológica da palavra risco e seus respectivos significados, diversos autores, dentre eles Pradier (2004) optaram por adotar a perspectiva de que 0 termo risco, além de difuso, designa uma transversalidade de saberes, de modo que "cada vez mais, se apresenta transiente e em constante mutação, devendo numa última análise ser encarado como um conceito, ele próprio em adaptação às realidades provisórias com as quais (co)-evoluímos" (LIND, 2011, p. 27).

A partir desse difusionismo etimológico Pradier (2004) argumenta que foram elaboradas duas teses para a identificação da gênese de utilização do termo risco. A primeira encontra-se na tese modernista baseada na perspectiva weberiana de um protestantismo de espírito capitalista e no pensamento marxista do desenvolvimento da classe burguesa, "onde uma classe social teria, assim, novas práticas que perturbariam a organização social e política" (PRADIER, 2004, p. 172, tradução nossa). Estes fatores serão defendidos por Luhmann (1993) e Giddens (2002) na tese modernista, vinculando a ideia de risco à expansão comercial e à gênese do capitalismo, que promove inovações fiscais e contábeis, além de preocupações sobre mercadorias, levando à criação dos seguros comerciais. A outra tese, de natureza náutica, embora não comprovada, conforme Pradier (2004), resguarda um vínculo etimológico com a palavra latina resecare (ressecar), que "teria evoluído para resecum (que corta) no latim popular e, daí, para "recife", associando-se a 'risco que corre uma mercadoria no mar"” (MENDES, 2015, p. 16).

Embora estudos estabeleçam que o uso da palavra risco teve sua origem relacionada a pelo menos dois contextos do século XII na Itália - um de característica jurídico-político associado às práticas militares e de caráter comercial; outro de natureza literária, no qual o risco encontra-se vinculado à figura do herói ou cavaleiro. A efetiva difusão do termo, contudo, ocorre a partir do século XVII, período no qual se associou, "agora sim, às atividades náuticas e, especificamente, aos seguros marítimos". (MENDES, 2015, p. 16). Por outro lado, as construções teóricas de caráter sociológico em torno do fenômeno buscam localizá-lo no interior da formação dos indivíduos, grupos e sociedades, contribuindo, neste caso, para o entendimento da denominada "sociedade do risco", tal como a proposição de Beck (2013). 
0 autor explicita seus pressupostos, propondo compreender o desenvolvimento da modernidade em duas fases. A primeira de caráter positivo e retrospectivo em relação ao futuro na definição da qualidade e controle do risco, a partir do Estado e de suas instituições políticas e disciplinares, as quais atuam, ainda, como instrumento científico e tecnológico na promoção, conhecimento e controle do risco. Nesse cenário, os séculos XIX e XX são decisivos para o entendimento de que:

\begin{abstract}
A história das instituições políticas da sociedade moderna dos séculos XIX e XX pode ser entendida como a criação conflituosa de um sistema legal para lidar com as incertezas e os riscos industriais fabricados, isto é, fruto de decisões. 0 cálculo de risco, o princípio do seguro e 0 Estado de bem-estar social possibilitam contratos de risco sancionados pelo Estado, isto é, institucionalizam promessas de segurança diante de um futuro desconhecido. (MOTTA, 2014, p 16)
\end{abstract}

A segunda fase da modernidade é caracterizada como originada da complexidade dos sistemas industriais, da crise do pensamento técnico-científico progressivo e linear, bem como das problemáticas sociais que enfatizam a luta de classes. Trata-se de uma "modernidade reflexiva, quando ela se confronta com as consequências de seu sucesso - a sociedade de risco" (MOTTA, 2014, p. 17). Assim, a perspectiva sociológica de caráter amplo, segundo Mendes (2015, p 19), "obriga a estudar e a atender às desigualdades associadas ao risco, e à forma como as sociedades contemporâneas estruturam a diferença social a partir da definição de populações em risco e de populações vulneráveis".

Do ponto de vista conceitual, propriamente dito, Lind (2011) apresenta a ideia de que o conceito de risco é sustentado por duas características - desconhecimento e necessidade de decisão. A primeira diz respeito ao critério de indeterminação dos acontecimentos, sendo necessário conhecer para controlar e evitar possíveis efeitos colaterais, uma vez que os "riscos existem porque (quando) existe um prejuízo como dano secundário a uma determinada decisão ou família de decisões” (LIND, 2011, p. 28). Isto ocasiona, para o autor, a identificação de uma característica implícita ao risco que é o juízo de valor. 0 desconhecimento, contudo, não implica necessariamente na ausência de conhecimento ou a sua qualidade, mas diz respeito à incapacidade de se conhecer tudo ou ter domínio total do conhecimento. Assim, "o Risco existe mesmo com conhecimento porque o conhecimento é sempre provisório e a verdade não é absoluta" (LIND, 2011, p. 28). A segunda característica é a ação consequente à tomada de conhecimento em relação a um evento ou acontecimento, de modo que os "riscos existem, porque - ou quando - existem diferentes possíveis alternativas numa tomada de decisão". (LIND, 2011, p. 28).

De modo geral, o risco pode ser entendido como uma categoria de representação analítica transdisciplinar das múltiplas manifestações indefinidas do presente e do futuro da modernidade que, do ponto de vista sociológico, caracteriza um "novo princípio organizador da sociedade" (MOTTA, 
2014, p. 16). Trata-se de uma "forma de pensar e de agir, envolvendo cálculos sobre um futuro provável que inspira ações no presente com o objetivo de controlar esse futuro potencial" (CALIMAN; TAVARES, 2013, p. 938).

0 risco no âmbito da governamentalidade "ter-se-ia transformado num conceito cultural e político através do qual indivíduos, instituições e grupos sociais são organizados, monitorizados e regulados" (CARVALHO, 2011, p. 80). As abordagens analíticas efetuadas por Lupton (2013) apresenta correntes cognitivas e tecno-científicas nas quais o risco é considerado um elemento matemático de uso na estatística, na engenharia e na economia.

Na perspectiva da governamentalidade, o risco é considerado uma estratégia de governo de caráter vigilante, disciplinador e regulatório da conduta dos indivíduos e da população, a partir de procedimentos e múltiplos dispositivos, a exemplo dos dispositivos de informação, dispositivo de arquivo e outros, que captam, coletam, processam, classificam e disseminam dados e informações que configuram verdadeiras “assemblage de risco". Nesse sentido, Mitchel Dean (1999) reconhece o risco como uma "racionalidade calculada", que nas palavras de Lupton (2013) configura uma:

Rede heterogênea de atores, instituições, conhecimentos e práticas interativas. Informações sobre diversos riscos são coletadas e analisadas por pesquisadores médicos, estatísticos, sociólogos, demógrafos, cientistas ambientais, profissionais da área jurídica, estatísticos, banqueiros e contadores, para citar apenas alguns (LUPTON, 2013, p. 117, tradução nossa).

Destacando o sentido associativo, Lupton (2013) considera que o risco pode ser tomado como um dispositivo, no sentido foucaultiano do termo, por reunir elementos discursivos e não-discursivos para o seu exercício de poder. Assim, "um dispositivo de risco cria uma relação específica com 0 futuro, que requer o monitoramento do futuro, a tentativa de calcular o que o futuro pode oferecer e a necessidade de controlar e minimizar seus efeitos potencialmente prejudiciais" (ARADAU; VAN MUNSTER, 2007, p. 98, tradução nossa).

0 surgimento da ideia de risco demarca uma ruptura entre uma perspectiva racionalizante, que privilegia o passado, para se dedicar ao futuro, de modo que a razão de registrar, que antes seria para conhecer, agora, além de conhecer é também para prever, antecipar e evitar o risco. Sob esse propósito, "as tecnologias de vigilância em massa, monitoramento, observação e medição são centrais para esse poder disciplinar, ajudando a construir entendimentos de corpos no espaço e no tempo e a usar esses entendimentos para regulá-Ios" (LUPTON, 2013, p. 116, tradução nossa). Se o risco é uma racionalização do futuro, tal projeção é baseada nas tecnologias de normalização, disciplina e vigilância que atuam como dispositivos de registros. Ocorre, a partir da articulação da noção de "registro" para 
o controle das ações do futuro, através do domínio da inventariação como instância de vigilância permanente, e da mediação do risco pela disciplinarização do conhecimento.

Nessa acepção de risco, ocorre uma inversão racional na produção de documentos, ao considerarmos que antes o registro estava direcionado ao passado, mas agora encontra-se voltado para o futuro: "no risco o passado perde o seu poder de determinar o presente. É o futuro, algo que é construído, não existente, que constrói o presente, e os riscos são sempre locais e globais, assumindo uma dimensão transescalar" (MENDES, 2015, p. 24). Dessa forma, é possível sustentar a racionalidade política do arquivo sob o enfoque de uma biopolítica que o considera como elemento de desejo de produção e registro, por meio do princípio da vigilância, cuja finalidade é controlar e coordenar as condutas sociais, através de uma concepção de risco.

Esse é o alicerce da articulação do conceito de risco com a abordagem racionalizada do arquivo. 0 risco apresenta-se como condição (instância) intermediária entre a segurança e 0 perigo. A predominância agora é a do futuro, em contraposição aos objetivos de lançar luz sobre o passado. Dessa forma, as práticas estatais de cálculo sistematizado, com base em critérios estatísticos, geram registros arquiváveis que, por sua vez, se colocam à disposição da política de controle e gestão de riscos. Assim, o risco configura-se como um dispositivo de compreensão e utilização de tecnologias de governo, por meio do qual se cria novas formas de Estado, tal como o estado de exceção, o terrorismo e a subjetividade de sujeitos de risco (terroristas). Para tanto, os efeitos do controle operam em mecanismos aperfeiçoados das técnicas de registro, que constroem dados informacionais, passando de simples registros notariais, administrativos, aos registros coletivos e cifrados de indivíduos (código e identidade). Doravante, o que se arquiva é o que se deseja preservar para os cuidados e usos futuros, de modo que ocorre o aperfeiçoamento da técnica, mas mantendo-se sob a égide do registro.

Os registros, tal como o monitoramento, revelam não apenas uma ação instrumental e política da administração, mas também do administrador e do arquivista. A arquivística como disciplina surgiria embasada nos esforços para promover o controle das informações individuais e estatais, tornando 0 arquivo ferramenta de vigilância, instituidora e mantenedora das forças de conservação e resistência do poder.

Partindo do pressuposto de que o arquivo é um espaço de vigilância, política e poder, Ketelaar (2007, p. 148, tradução nossa) reconhece que este poder também pertence ao cidadão o qual "é protegido pelo poder do arquivista, que é capaz de combater a fraude, a violência ou simplesmente negligenciar com coragem profissional". É concedido ao arquivista, portanto, exercer inúmeros papéis: 
guardião, cúmplice da opressão, fiel da justiça ou titular do conhecimento-poder. Sob essa égide, 0 arquivo funcionará, muitas vezes, como um espaço reservado que, após a descoberta por outros mecanismos de vigilância, conseguirá aumentar a zona de saber indispensável ao poder disciplinar. Contudo, os arquivistas podem operar procedimentos que rivalizem com o poder político instituído, a partir do momento que considera o seu ofício como um "regime de práticas" que varia no tempo e no espaço, ou seja, uma "arquivalização" que se caracteriza pela percepção, identificação e articulação, consciente ou inconsciente, de aspectos sociais, políticos e culturais "que faz considerar que alguma coisa merece ser arquivada" (KETELAAR, 2018, p. 198).

É no arquivo, portanto, enquanto máquina heterotópica de acoplamento informacional, temporal e prática de governo, que se tornariam possíveis o processamento de ações políticas e infocomunicacionais baseadas na cronologia dos acontecimentos, na dispersão dos espaços e na multiplicidade dos sujeitos. Nesse prisma, seria possível perceber os arquivos enquanto dispositivos de poder estratégico de ações de governamentalidade.

\section{CONSIDERAÇÕES FINAIS}

Uma das características da modernidade seria a condição de imprevisibilidade e de incerteza definida pela noção de risco, acompanhada de uma racionalidade acerca do futuro, que busca manter 0 equilíbrio entre o risco do presente e a tentativa de evitar o improvável, o incalculável, o novo, através de uma convergência maquínica de registro de todas as coisas.

Neste contexto, a importância do arquivo no âmbito da modernidade e da biopolítica, decorre do seu efeito de "arquivalização". A partir desta compreensão, tais espaços e seus registros podem ser considerados como elementos maquínicos; o documento seria a máquina de escrita, por se constituir como continuidade intempestiva do ato executado, enquanto 0 arquivo seria máquina de representação, por meio do qual as práticas de classificação e representação dariam continuidade extensiva ao registro documental. Dessa forma, considera-se que há neste processo uma relação na qual convergem e divergem múltiplos atores: produtores, objetos, instituições, profissionais de informação e registro, bem como estratégias, saberes e "dispositivos" que, deixando suas marcas ou rastros, estabelecem uma rede de significados que constitui e desloca, de uma ponta à outra da "intervenção arquival", o documento.

A modernidade estabelece no arquivo a capacidade de atuar no limite das tentativas de solidificação do real, ainda que se reconheça sua diluição no ar, através do registro informacional e 
de ações hermenêuticas indexadoras das condições sociais. Neste caso, os critérios de classificação e representação da informação, por exemplo, atuam como suplemento que ampliam e reduzem, simultaneamente, a capacidade de atuação social dos documentos. Desta maneira, portanto, ao mesmo tempo que o registro integra, ele também amplia e tensiona as capacidades de ação do documento, sobretudo, quando se considera que a sua dimensão informacional está situada no entre-lugar que identifica o dentro e o fora do documento.

Assim, na perspectiva de uma biopolítica, estas práticas funcionam ao modo "panóptico", "Superpanóptico" e/ou "vigilância de dados", que possibilitam a indexação do conjunto populacional, ou caso queiramos atualizar as noções e abordagens, a dispersão de perfis de usuários produtores, agenciadores, difusores e consumidores informacionais. Acresce a isso o fato dessa perspectiva contribuir, ainda para o entendimento de que a informação, inclusive a digital, na "governamentalidade algorítmica", é o elemento permanente-móve/ de produção de documentos, sujeitos, ou em tudo mais, devires. Contudo, reconhecendo a atual zona de fronteira que aproxima os modelos gerenciais orgânicos e os modelos gerenciais complexos e dispersivos, alguns critérios inerentes à informação arquivística se amplificam, a exemplo das noções de autoria (autor único ou autor composto?), proveniência (origem única ou múltipla origem?), valor (dentro ou fora do documento?), dentre outras.

Portanto, ao maximizar seus efeitos através do reconhecimento de tudo aquilo que é possível registrar, avaliar, classificar, representar, conservar e disseminar, diminuindo ou ampliando as capacidades de governança, seja por entes estatais ou entes privados, a prática biopolítica no arquivo converte a dimensão objetiva e material dos indivíduos, objetos, técnicas, instituições e coisas, em categorias funcionais que compõe, associam-se, destroem e criam máquinas e efeitos informacionais.

\section{REFERÊNCIAS}

ARADAU, C.; VAN MUNSTER, R. Governing terrorism through risk: taking precautions, (un) knowing the future. In: European Journal of International Relations, v. 31, n. 1, 2007, p. 89 115.

BARRY, A; OSBORNE, T; ROSE, N. Foucault and political reason: liberalism, neo-liberalism and rationalities of government. Chicago: The University of Chicago Press, 1996.

BECK, U. Sociedade de risco: rumo a uma outra modernidade. Rio de Janeiro: Editora 34, 2013.

BENTHAM, J. O Panóptico ou a Casa de Inspeção. In: TADEU, T. (org.). 0 Panóptico/Jeremy

Bentham. 2. ed. Belo Horizonte: Autêntica Editora, 2008. 
BURKE, P. Os usos da alfabetização no início da Itália moderna. In: BURKE, P.; PORTER, R. (org.). História social da linguagem. Tradução A. Hattnher. São Paulo: Ed. UNESP, 1997. (Unesp/ Cambridge). p. 15-41.

BURKE, P. Uma história social do conhecimento: de Gutemberg a Diderot. Rio de Janeiro: Jorge Zahar Ed., 2003.

CALIMAN, L. V; TAVARES, G. M. 0 Biopoder e a Gestão dos Riscos nas Sociedades Contemporâneas. Psicologia: Ciência e Profissão, v. 33, n. 4, 2013, p. 934-945.

CARVALHO, M. Risco: implicações sociais e éticas. In: ALBUQUERQUE, T; BRANCO, R. F; LIND, P. G. Risk: Reflexão e debate interdisciplinar entre doutorandos e pós-docs. Casa de Mateus Doc II. Lisboa: Instituto Internacional Casa de Mateus, 2011.

CASTRO, E. Vocabulário de Foucault. Tradução de Ingrid Müller Xavier. Belo Horizonte: Autêntica Editora, 2009.

CLARKE, R. Information Technology and Dataveillance. Communications of the ACM, v. 31, n. 5, 1988.

CLARKE, R; GREENLEAF, G. Dataveillance Regulation: A Research Framework. UNSW Law Research Paper No. 17-84, 2017.

DEAN, M. Governmentality: power and rule in modern society. Londres: Sage, 1999.

DERRIDA, J. Mal de Arquivo: uma impressão freudiana. Rio de Janeiro: Relume Dumará, 2001.

FOUCAULT, M. Vigiar e punir: nascimento da prisão. 29. ed. Petrópolis, Rio de Janeiro: Vozes, 2004.

FOUCAULT, M. Em defesa da sociedade: Curso no Collège de France (1975 - 1976). São Paulo: Ed. Martins Fontes, 2005.

FOUCAULT, M. Segurança, território, população. Curso dado no Collège de France (1977-1978). São Paulo: Martins Fontes, 2008.

FRIEDRICH. M. The Birth of the Archive: a history of knowledge. Michigan, EUA: University of Michigan Press, 2018.

GANDY JR., O. H. Coming to Terms with the Panoptic Sort. In: LYON, David; ZUREIK, Elia (orgs.) Computers, Surveillance and Privacy. Minneapolis: University of Minnesota Press, 1966.

GANDY JR., O. H. The panoptic sort. A political economy of personal information. Boulder: Westview Press. 1993.

GIDDENS, A. Runaway world: how globalization is reshaping our lives. London: Profile Books, 2002.

KETELAAR, E. The panoptical archive. In: BLOUIN JR, Francis X.; ROSENBERG, WILLIAM G.

Archives, documentation and institutions of social: memory essays from the Sawyer Seminar. The University of Michigan Press, 2007. 
KETELARR, E. (Des)construir o arquivo. In: HEYMANN, Luciana; NEDEL, Letícia (org.). Pensar os Arquivos: uma antologia. Rio de Janeiro: FGV Editora, 2018.

LATOUR, B. Cognição e visualização. Pensando com olhos e mãos. Trad. David Palacios. Terra Brasilis (Nova Série), v. 4, p. 1-40, 2015. Disponível em: http://journals.openedition.org/ terrabrasilis/1308. Acesso em: 22 jul 2020.

LIND, P. G. Risco em adaptação: da percepção do Risco à sua quantificação e controlo. In: ALBUQUERQUE, T; BRANCO, R. F; LIND, P. G. Risk: Reflexão e debate interdisciplinar entre doutorandos e pós-docs. Casa de Mateus Doc II. Lisboa: Instituto Internacional Casa de Mateus, 2011.

LUHMANN, N. Risk: a sociological theory. New York: de Gruyter, 1993.

LUPTON, D. Risk. 2 ed. Abingdon: Routledge, 2013.

MACHADO, R. Ciência e saber: a trajetória da arqueologia de Foucault. Rio de Janeiro: Edições Graal, 1982.

MENDES, J. M. Sociologia do risco: uma breve introdução e algumas lições. Coimbra: Imprensa da Universidade de Coimbra, 2015.

MOTTA, R. Risco e Modernidade: uma nova teoria social? In: Revista Brasileira de Ciências Sociais, v. 29, n. 86, 2014.

PARRA, H. Abertura e controle na governamentalidade algorítmica. Cienc. Cult. São Paulo, v. 68, n. 1, p. 39-49, mar. 2016. Disponível em: http://cienciaecultura.bvs.br/scielo.php?script=sci_ arttext\&pid=S0009-67252016000100013\&Ing=en\&nrm=iso. Acesso em: 26 out 2017.

PRADIER, Pierre-Charles. Histoire du risque. In: SANTOS DEL CERRO, J.; SECADES, M. G. História de la Probabilidad y la Estadística (II). Zaragoza: Delta Publicaciones, 2004.

POSTER, M. The Mode of Information: Poststructuralism and Social Context. Cambridge: Polity Press, 2007.

ROUVROY, A; BERNS, T. Governamentalidade algorítmica e perspectivas de emancipação: 0 díspar como condição de individuação pela relação?.Revista ECO-Pós, [S.I.], v. 18, n. 2, p. 36-56, out. 2015. ISSN 2175-8689. Disponível em: https://revistas.ufrj.br/index.php/eco_pos/article/view/2662. Acesso em: 10 ago 2016.

TAVARES, D. W. da S. Dispositivos de Informação: arquivos, memórias e informação. Dissertação (Mestrado em Ciência da Informação). Programa de Pós-graduação em Ciência da Informação, PPGCI, Universidade Federal da Paraíba, 2015.

WEBER, M. Economia e Sociedade: fundamentos da sociologia compreensiva. Brasília: Editora Universidade de Brasília, 2012.

ZUBOFF, S. In the Age of the Smart Machine. New York: Basic Books, 1988. 